\title{
Introduced forage species herbage dry matter production and chemical composition at two moist savannah sites in Ghana
}

\author{
$P$ Barnes
}

Animal Research Institute, PO Box 20, Achimota, Ghana

Two batches of introduced forage species whose seed were provided by ILCA's gene bank were evaluated for adaptation and dry matter production at two sites, one in the coastal savannah and the other in the guinea savannah zone of Ghana in two years. The first batch of forage materials made up of 20 legumes were evaluated in 1992 at the two sites and the second batch of forage materials made of six legumes and three grasses were evaluated in 1993 again at the two sites. In 1992 chemical analysis of the forages under test was conducted at Nyankpala, the guinea savannah zone site. The evaluation showed that in 1992 at both sites the highest yielding in herbage production were Stylosanthes scabra, Macrotyloma axillare, Stylosanthes hamata, Lablab purpureus and Stylosanthes guianensis yielding in excess of 2 tonnes per hectare. In 1993 the same legumes yielded herbage heavily at both sites but among the grasses in that trial Chloris gayana and Brachiaria ruziziensis were outstanding in yield than Panicum maximum. Chemical analysis in the first trial showed that the entries Centrosema pubescens, Lablab purpureus, Macrotyloma axillare, Neonotonia wightii and Stylosanthes guianensis have high amounts of both macro and micro-nutrients.

Nitrogen content $(\%)$ and some macro and micro-elements composition $(\mathrm{mg} / \mathrm{kg})$ of forage entries in trial one (1992) at Nyankpala

\begin{tabular}{|c|c|c|c|c|c|c|c|c|c|c|c|}
\hline \multirow[t]{2}{*}{ Entry (species) } & \multirow[t]{2}{*}{ ILCA $n^{\circ}$} & $\mathrm{N}$ & \multicolumn{9}{|c|}{$\begin{array}{l}\text { Chemical composition macro and } \\
\text { micro-elements, } \mathrm{mg} / \mathrm{kg} \text { (air-dry) }\end{array}$} \\
\hline & & $(\%)$ & $\mathrm{Ca}$ & $P$ & $\mathrm{Na}$ & $\mathrm{Mg}$ & $\mathrm{Mn}$ & $\mathrm{Zn}$ & $\mathrm{Cu}$ & $\mathrm{Fe}$ & K \\
\hline Centrosema brasilianum & 6773 & 1.63 & 9669 & 1072 & 62.9 & 272 & 285 & 33 & 7 & 331 & 4261 \\
\hline Centrosema pascuorum & 6774 & 1.47 & 8106 & 822 & 385.4 & 272 & 296 & 30 & 7 & 528 & 5056 \\
\hline Centrosema pubescens & 219 & 2.22 & 12583 & 1217 & 43.0 & 351 & 268 & 40 & 10 & 540 & 4787 \\
\hline Chamaecrista rotundifolia & 9288 & 1.53 & 7442 & 837 & 39.9 & 262 & 252 & 30 & - & 1093 & 2800 \\
\hline Clitoria ternatea & 9291 & 1.59 & 4252 & 916 & 395.3 & 615 & 342 & 43 & 7 & 438 & 5996 \\
\hline Desmodium intortum & 104 & 1.58 & 6898 & 929 & 52.8 & 254 & 148 & 40 & - & 1023 & 5193 \\
\hline Desmodium uncinatum & 6765 & 1.79 & 6844 & 883 & 42.8 & 270 & 220 & 30 & - & 1016 & 4330 \\
\hline Lablab purpureus & 147 & 2.09 & 8878 & 1190 & 46.2 & 271 & 92 & 30 & - & 373 & 4987 \\
\hline Macroptilium atropurpureum & $n 69$ & 1.83 & 6766 & 768 & 33.0 & 412 & 109 & 30 & - & 776 & 4657 \\
\hline Macrotyloma axillare & 6756 & 2.30 & 11320 & 1014 & 33.0 & 376 & 469 & 49 & 7 & 696 & 4056 \\
\hline Neonotonia wightii & 6761 & 2.48 & 11993 & 1557 & 39.9 & 409 & 242 & 40 & - & 438 & 3060 \\
\hline Rhynchosia minima & 13935 & 1.81 & 7171 & 899 & 103.95 & 326 & 395 & 39 & 7 & 760 & 3198 \\
\hline Stylosanthes guianensis & 4 & 1.90 & 9435 & 918 & - & 312 & 276 & 40 & 10 & 794 & 6254 \\
\hline Stylosanthes guianensis & 163 & 2.20 & 9036 & 1171 & 36.5 & 319 & 289 & 13 & 10 & 860 & 625 \\
\hline Stylosanthes hamata & 75 & 1.55 & 11941 & 682 & 46.1 & 263 & 145 & 23 & - & 243 & 4990 \\
\hline Stylosanthes hamata & 167 & 1.20 & 9172 & 606 & 59.6 & 232 & 232 & 36 & 6 & 354 & 373 \\
\hline stylosanthes scabra & 441 & 1.63 & 14106 & 663 & 1033.1 & 245 & 139 & 70 & - & 1265 & 4663 \\
\hline Vigna unguiculata & 9333 & 2.39 & 11761 & 1286 & 697.7 & 462 & 385 & 60 & 10 & 601 & 8511 \\
\hline Zornia latifolia & 172 & 2.29 & 5265 & 1365 & 59.6 & 252 & 232 & 46 & 7 & 871 & 5526 \\
\hline
\end{tabular}

